Evgenia G. Karousou ${ }^{1}$ Maria Militsopoulou ${ }^{2}$ Giovanni Porta ${ }^{1}$ Giancarlo De Luca ${ }^{1}$ Vincent C. Hascall ${ }^{3}$ Alberto Passi ${ }^{1}$

${ }^{1}$ Department of Experimental and Clinical Biomedical Sciences, University of Insubria,

Varese, Italy

${ }^{2}$ Department of Chemistry, Section of Organic Chemistry, Biochemistry and Natural Products, Laboratory of Biochemistry, University of Patras,

Patras, Greece

${ }^{3}$ Department of Biomedical Engineering and Orthopedic Research Center, Lerner Research Institute, Cleveland Clinic Foundation, Cleveland, $\mathrm{OH}, \mathrm{USA}$

\section{Polyacrylamide gel electrophoresis of fluorophore- labeled hyaluronan and chondroitin sulfate disaccharides: Application to the analysis in cells and tissues}

This report describes a new formulation of polyacrylamide gel electrophoresis of fluorophore-labeled saccharides (PAGEFS) for the analysis of hyaluronan (HA) and chondroitin sulfate (CS) $\Delta$-disaccharides. PAGEFS relies on derivatization of reducing ends of HA- and the variously sulfated CS-derived $\Delta$-disaccharides with 2-aminoacridone (AMAC), followed by electrophoresis under optimized buffer conditions (Tris-borate and Tris- $\mathrm{HCl}$ ) and on polyacrylamide gels (25\% T/3.75\% C). The method was applied to the analysis of glycosaminoglycans (GAGs) from the human umbilical cord tissue and GAGs isolated from human aortic smooth muscle cell cultures. The obtained results were in agreement with those obtained after an analysis with high-performance liquid chromatography (HPLC). On the basis of these results, PAGEFS is a rapid and sensitive method for the analysis of the total amount of HA- and CS-derived disaccharides, as it allows analyzing 20 samples in minigels in one run and provides quantitation with relatively high sensitivity (less than 25 pmol per disaccharide). In addition, PAGEFS overcomes the lack of commercial gels described previously for the separation of AMAC-labeled disaccharides. Therefore, the method proposed here is an economic and useful tool for a fast screening of GAGs in biological samples, particularly when a high number of samples should be analyzed.

Keywords: Chondroitin sulfate disaccharides / Human aortic smooth muscle cells / Human umbilical cord / Hyaluronan disaccharides / Polyacrylamide gel electrophoresis

DOI 10.1002/elps.200406034

\section{Introduction}

Glycosaminoglycans (GAGs) are linear heteropolysaccharides composed of repeating disaccharide units. They can be divided into four main categories: (i) hyaluronan (HA), (ii) chondroitin sulfate (CS) and dermatan sulfate (DS), (iii) heparan sulfate (HS) and heparin, and (iv) keratan sulfate. With the exception of HA, GAGs contain sulfate residues and are covalently bound to a protein core, constituting proteoglycans (PGs), which are the main complex macromolecules of many extracellular matrices (ECMs). They play important biological roles as they participate in and regulate many cellular events, including

Correspondence: Prof. Alberto Passi, Department of Experimental and Clinical Biomedical Sciences, University of Insubria, via Dunant 5, I-21100 Varese, Italy

E-mail: alberto.passi@uninsubria.it

Fax: $+39-0332-217119$

Abbreviations: AMAC, 2-aminoacridone; AoSMC, human aortic smooth muscle cell; CS, chondroitin sulfate; FACE, fluorophoreassisted carbohydrate electrophoresis; GAG, glycosaminoglycan; HA, hyaluronan; PAGEFS, polyacrylamide gel electrophoresis of fluorophore-labeled saccharides cell proliferation, migration, and adhesion [1]. CS, usually referred to as galactosaminoglycan (GalAG), consists of a repeating disaccharide unit that contains an uronic acid glycosidically linked to a galactosamine residue. It is a highly charged polymer due to the presence of esterified sulfate groups at one or more available hydroxyl groups on the disaccharide [2]. CS sulfated at the C-4 and the C-6 positions of $N$-acetylated galactosamine (GalNAc) are predominant GAGs in the ECM of the arterial wall, and the modification of $\Delta$ di-mono $4 S / \Delta$ di-mono6S ratio plays a critical role in diseases [3-6]. HA is the simplest GAG since none of the hydroxyl groups are esterified with sulfates. Its structure differs from CS in that the GalNAc is replaced with $N$-acetylated glucosamine (GlcNAc). It is not covalently bound to a protein core, but it forms aggregates with $\mathrm{PGs}$ of high molecular size, such as aggrecan and versican. It plays an important role in cellular events, in embryonic and tissue development as well as in tumorigenesis and in several diseases [7].

Since CS and HA are components with high importance in biological events, we developed a technique for the analysis of $\Delta$-disaccharides obtained after polysaccha- 
ride chain digestion with specific enzymes. This method involves derivatization of the enzymatically released unsaturated disaccharides with the fluorophore 2-aminoacridone (AMAC), followed by electrophoresis in minislab polyacrylamide gel. Polyacrylamide gel electrophoresis of fluorophore-labeled saccharides (PAGEFS) has been previously described for analysis of $N$-linked glycans of mammalian [8], as well as fluorophore-assisted carbohydrate electrophoresis (FACE) for analysis of total hyaluronan and chondroitin sulfate $[9,10]$ and polysaccharide analysis using carbohydrate gel electrophoresis (PACE) for analysis of plant polysaccharides [11]. Gel electrophoresis using minislab gels is a relatively economical, easy, and fast method. Many samples can be analyzed in parallel, giving it the potential for a high throughput, and quantitation of a total amount of GAGs is determined when standards are analyzed in the same gel.

The aim of this study is to present a new formulation of polyacrylamide gel electrophoresis useful for GAG analysis, and to compare the results of this technique with those of the well-established HPLC. The sensitivity of the developed PAGEFS method was found to be less than 25 pmol per disaccharide. Both separation techniques were applied to the analysis of HA and CS isolated from human umbilical cord and cultured human aortic smooth muscle cells (AoSMCs). It was worth studying these samples, as changes in CS and HA content in the ECM are involved in several pathologic conditions in the human umbilical cord and arterial wall [4, 12].

\section{Materials and methods}

\subsection{Chemicals and biological materials}

Standard preparations of 2-acetamido-2-deoxy-3-O-(4deoxy- $\alpha$-L-threo-hex-4-enopyranosyluronic acid)-D-glucose [ $\Delta$ di-non $\left.S_{H A}\right]$, 2-acetamido-2-deoxy-3-O-(4-deoxy2-O-sulfo- $\alpha$-L-threo-hex-4-enopyranosyluronic acid)-4O-sulfo-D-galactose [ $\Delta$ di-di(2,4)S], 2-acetamido-2-deoxy3-O-(4-deoxy- $\alpha$-L-threo-hex-4-enopyranosyluronic acid)4-O-sulfo-D-galactose [ $\Delta$ di-mono4S], 2-acetamido-2deoxy-3-O-(4-deoxy- $\alpha$-L-threo-hex-4-enopyranosyluronic acid)-6-O-sulfo-D-galactose [ $\Delta$ di-mono6S], 2-acetamido-2-deoxy-3-O-(4-deoxy-2-O-sulfo- $\alpha$-L-threo-hex-4enopyranosyluronic acid)-D-galactose [ $\Delta$ di-mono2S] and 2-acetamido-2-deoxy-3-O-(4-deoxy- $\alpha$-L-threo-hex-4enopyranosyluronic acid)-D-galactose $\left[\Delta\right.$ di-nonS $\left.S_{C S}\right]$ were all purchased from Sigma (St. Louis, MO, USA). Protease $\mathrm{K}$ (EC 3.4.21.64) was from Finnzymes (Espoo, Finland). Hyaluronidase SD (EC 3.2.1.35) and chondroitinase ABC (EC 4.2.2.4) were from Seikagaku Kogyo (Tokyo, Japan).
AMAC was obtained from Molecular Probes (Eugene, OR, USA) and $\mathrm{NaBH}_{3} \mathrm{CN}$ from Sigma-Aldrich (Steinheim, Germany). Tris was from Fluka Chemie (Buchs, Switzerland) and acetonitrile from Merck (Darmstadt, Germany). Acrylamide and $N, N$ '-methylenebisacrylamide were obtained from Bio-Rad (Richmond, CA, USA), TEMED from BDH Chemicals (Poole, England), and ammonium persulfate from LKB (Bromma, Sweden). All aqueous solutions were prepared using water filtered through a Milli- $Q$ water system (Millipore, Bedford, MA, USA). All other chemicals used were of analytical reagent grade.

\subsection{Derivatization procedure}

Derivatization of standard $\mathrm{HA}$ and CS $\Delta$-disaccharides was done as described by Calabro et al. [13]. In particular, $10 \mathrm{nmol}$ of each standard $\Delta$-disaccharide in water was completely evaporated in a microcentrifuge tube at $11000 \times g$ at room temperature. A $40 \mu \mathrm{L}$ volume of $12.5 \mathrm{~mm}$ AMAC solution in glacial acetic acid/DMSO (3:17 v/v) was added, and samples were incubated for 10-15 min at room temperature. A $40 \mu \mathrm{L}$ volume of a freshly prepared solution of $1.25 \mathrm{M} \mathrm{NaBH}_{3} \mathrm{CN}$ in water was added to each sample followed by an overnight incubation at $37^{\circ} \mathrm{C}$.

\subsection{Preparation of polyacrylamide gel}

A MiniProtean II cell vertical slab gel electrophoresis apparatus (Bio-Rad) was used with $7.2 \mathrm{~cm}$ plates, $0.75 \mathrm{~mm}$ spacer, and wells of $0.5 \mathrm{~cm}$. The stock buffer solutions were $1.5 \mathrm{~m}$ Tris-borate, $\mathrm{pH} 8.8$, and $1.5 \mathrm{M}$ Tris$\mathrm{HCl}, \mathrm{pH}$ 8.8. Acrylamide solution $50 \% \mathrm{~T} / 7.5 \% \mathrm{C}$ for the resolving gel and $50 \% \mathrm{~T} / 15 \% \mathrm{C}$ for the stacking gel were used as stock solutions. $\%$ T refers to the total concentration $(\mathrm{w} / \mathrm{v})$ of acrylamide monomer (i.e. acrylamide plus methylenebisacrylamide);\% C refers to the concentration $(\mathrm{w} / \mathrm{v})$ of cross-linker relative to the total monomer. A $10 \mathrm{~mL}$ volume of $25 \% \mathrm{~T} / 3.75 \% \mathrm{C}$ resolving gel, in $187.5 \mathrm{~mm}$ Trisborate and $187.5 \mathrm{~mm}$ Tris- $\mathrm{HCl}$ buffer solution (final concentrations) was prepared and degassed. A $5 \mu \mathrm{L}$ volume of TEMED and a $50 \mu \mathrm{L}$ volume of a freshly prepared $10 \%$ $w / v$ ammonium persulfate were added. The solution was mixed rapidly and then placed between the glass plates, avoiding air bubbles. The nonpolymerized gel was overlaid with butanol. Polymerization occurred within $\sim 20 \mathrm{~min}$. The gel can be used immediately or stored at $4^{\circ} \mathrm{C}$ for $1-2$ weeks. The resolving gel upper surface was rinsed with stacking gel buffer $(0.15 \mathrm{~m}$ Tris- $\mathrm{HCl}$ diluted from the stock solution). A $5 \mathrm{~mL}$ volume of $5 \% \mathrm{~T} / 1.5 \% \mathrm{C}$ acrylamide stacking gel in $0.36 \mathrm{M}$ Tris- $\mathrm{HCl}$ buffer solution was prepared, followed by an addition of $10 \mu \mathrm{L}$ TEMED and $50 \mu \mathrm{L} 10 \%$ ammonium persulfate. Immediately the 
solution was poured on the top of the resolving gel and the well-forming comb was inserted. The height of the stacking gel was $5 \mathrm{~mm}$, and the polymerization required $\sim 45$ min.

\subsection{Electrophoresis of $\Delta$-disaccharides}

Immediately before electrophoresis, the wells were rinsed with the electrophoresis buffer ( $0.15 \mathrm{M}$ Tris-borate, $\mathrm{pH} 8.8)$. A prerun of the gel was done at $400 \mathrm{~V}$ and $4^{\circ} \mathrm{C}$ for $10 \mathrm{~min}$ in order to stabilize the current. A $5 \mu \mathrm{L}$ volume of each sample, supplemented with glycerol in a final concentration of $20 \% \mathrm{v} / \mathrm{v}$, was loaded in each well. A marker sample containing bromophenol blue was also run in a well with no sample. Electrophoresis was done at $400 \mathrm{~V}$ and $4^{\circ} \mathrm{C}$ and terminated when the marker dye was $1.2 \mathrm{~mm}$ from the bottom of the gel ( $\sim 35 \mathrm{~min})$.

\subsection{Gel imaging and product quantitation}

Gels were scanned in a UV-light box using a CCD camera (Gel Doc 2000 System) from Bio-Rad Laboratories. Identification and quantitation of sample bands were done by comparing their migration and the pixel density with standard $\Delta$-disaccharides, running in the same gel.

\subsection{HPLC analysis}

Separation and analysis of AMAC-derivatives of $\Delta$-disaccharides were done with a Jasco-Borwin chromatograph system with a fluorophore detector (Jasco FP-920, $\lambda$ ex = $442 \mathrm{~nm}$ and $\lambda \mathrm{em}=520 \mathrm{~nm}$ ). Chromatography was carried out using a reversed-phase column (C-18, 4.6 × $150 \mathrm{~mm}$; Bischoff) at room temperature, equilibrated with $0.1 \mathrm{M}$ ammonium acetate, $\mathrm{pH} 7.0$, filtered through a $0.45 \mu \mathrm{m}$ membrane filter. A gradient elution was done using a binary solvent system composed of $0.1 \mathrm{M}$ ammonium acetate, pH 7.0 (eluent A), and acetonitrile (eluent B). The flow rate was $1 \mathrm{~mL} / \mathrm{min}$, and the following program was used: prerun of column with $100 \%$ eluent $A$ for 20 min, isocratic elution with $100 \%$ eluent $A$ for 5 min, gradient elution to $30 \%$ eluent B for 30 min and from $30 \%$ to $50 \%$ for 5 min. Sample peaks were identified and quantified comparing the fluorescence spectra with standard $\Delta$-disaccharides, using Jasco-Borwin software.

\subsection{Cell culture}

Human aortic smooth muscle cells (AoSMCs) and their growth medium Bulletkit-2 (SmGM-2) were obtained from Clonetics $^{\mathrm{TM}}$ (BioWhittaker, Walkersville, MD, USA) as well as all the other reagents. Cells $\left(10^{5}\right)$ were seeded in a T-25 flask, and the growth medium was changed daily. The cells were subcultured at early confluence using trypsin/EDTA. The trypsin was inactivated with trypsin neutralize solution (TNS), and the number of cells in suspension was determined using a Burker chamber. A number of $5 \times 10^{4}$ cells was seeded in a well plate, and the culture was maintained at $37^{\circ} \mathrm{C}\left(5 \% \mathrm{CO}_{2}\right.$ in air with $90 \%$ humidity) in the SmGM-2 medium. The medium was changed daily over a week. Cell-layer samples and media were harvested daily. Cell-layer samples were extracted with $2 \%$ SDS.

\subsection{Isolation and degradation of GAGs from cell culture and tissue}

Medium and cell-layer extracts from the cell cultures were frozen at $-80^{\circ} \mathrm{C}$ and lyophilized in a microfuge tube at room temperature. Each pellet was dissolved in $300 \mu \mathrm{L}$ water followed by an addition of $96 \%$ ethanol (or absolute ethanol) in a ratio of 1:4. The mixtures were precipitated overnight at $-20^{\circ} \mathrm{C}$. Following centrifugation at $11000 \times g$ at $4^{\circ} \mathrm{C}$ for $15 \mathrm{~min}$, the pellets were left to dry and then digested with protease K. In particular, the pellet was dissolved in $300 \mu \mathrm{L} 100 \mathrm{~mm}$ ammonium acetate buffer, $\mathrm{pH} 7.0$, containing $20 \mathrm{U} / \mathrm{mL}$ protease $\mathrm{K}$, and digestion was done at $60^{\circ} \mathrm{C}$ for $2 \mathrm{~h}$. The enzymic treatment was terminated by boiling for 5 min. Thereafter, 4 volumes of $96 \%$ ethanol per sample volume was added, and the GAGs in the mixture were precipitated at $-20^{\circ} \mathrm{C}$ overnight. Fresh human umbilical cord samples $(50 \mathrm{mg})$ were digested at $60^{\circ} \mathrm{C}$ for $2 \mathrm{~h}$ in $300 \mu \mathrm{L} 100 \mathrm{~mm}$ ammonium acetate buffer, $\mathrm{pH} 7.0$, containing $20 \mathrm{U} / \mathrm{mL}$ protease $\mathrm{K}$. The enzymic treatment was terminated by boiling for $5 \mathrm{~min}$. Four volumes of $96 \%$ ethanol per sample volume was added, and the GAGs in the mixture were precipitated at $-20^{\circ} \mathrm{C}$ overnight. Ethanol-precipitated GAGs were centrifuged at $11000 \times g$ at $4^{\circ} \mathrm{C}$ for $15 \mathrm{~min}$. The obtained pellets were dried and dissolved in $100 \mu \mathrm{L} 100 \mathrm{~mm}$ ammonium acetate, $\mathrm{pH} 7.0$, containing $100 \mathrm{mU} / \mathrm{mL}$ hyaluronidase SD and digested at $37^{\circ} \mathrm{C}$ for 1 h. A $100 \mathrm{mU} / \mathrm{mL}$ chondroitinase $A B C$ was added, and the mixture was incubated at $37^{\circ} \mathrm{C}$ for $3 \mathrm{~h}$. The samples were then frozen at $-80^{\circ} \mathrm{C}$ and then lyophilized. The $\Delta$-disaccharide digested products were then derivatized as described above.

\section{Results and discussion}

It has already been reported that derivatization of $\mathrm{HA}$ and CS $\Delta$-disaccharides with AMAC improve dramatically the detection sensitivity of various separation techniques, such as HPLC, FACE, and CZE [13-15]. Derivatization 
with AMAC has also been recently used to study polysaccharides found in plant walls [11]. This method allows the labeling of the reducing ends of unsaturated disaccharides obtained after enzymic degradation of GAG chains [16]. The amino group of AMAC reacts with the carbonyl group of the reducing end of the disaccharide moiety to form a Schiff's base, further reduced with sodium cyanoborohydride to form a stable secondary amine [14]. AMAC derivatives are stable for months when stored at $-80^{\circ} \mathrm{C}[17]$.

\subsection{Optimization of gel electrophoresis}

Gel electrophoresis was optimized for HA and variously sulfated CS $\Delta$-disaccharides. The gels used always consisted of a stacking gel and a resolving gel. The stacking gel is important as it facilitates the uniform entry of samples into the resolving gel and furthermore retards the excess AMAC. Following pilot experiments it was found that the optimal heights of the stacking and resolving gels were $5 \mathrm{~mm}$ and $5.5 \mathrm{~cm}$, respectively. In order to optimize the electrophoretic conditions, various running conditions were tested. These involved the percentage of acrylamide in the gels, the concentration of $N, N^{\prime}-$ methylenebisacrylamide in the gels and the type of electrophoresis buffer. All values of the acrylamide concentration between 25 and $30 \%$ in the resolving gel separated completely the disaccharides tested (data not shown). However, the concentration of the cross-linker ( $N, N^{\prime}$-methylenebisacrylamide) was crucial for effective separation. Four different concentrations of cross-linkers were tested in the resolving gel: (i) $25 \% \mathrm{~T} / 2.5 \% \mathrm{C}$, (ii) $25 \% \mathrm{~T} / 3.75 \% \mathrm{C}$, (iii) $25 \% \mathrm{~T} / 5 \% \mathrm{C}$, and (iv) $25 \% \mathrm{~T} / 7.5 \% \mathrm{C}$. The results showed that the gel composed of $25 \% \mathrm{~T} / 3.75 \% \mathrm{C}$ ensured the best separation of the $\Delta$-disaccharides (Fig. 1). Gels with a higher concentration of cross-linker were less efficient (data not shown). The ratios that were examined for the stacking gel were: (i) $5 \% \mathrm{~T} / 0.5 \% \mathrm{C}$, (ii) $5 \% \mathrm{~T} / 1 \% \mathrm{C}$, (iii) $5 \% \mathrm{~T} / 1.5 \% \mathrm{C}$. The optimal value was $5 \% \mathrm{~T} / 1.5 \% \mathrm{C}$, indicating that the cross-linker concentration was also crucial in the stacking gel (data not shown).

As shown in Fig. 2, almost identical molar fluorescence was obtained for both $\Delta$ di-nonS $S_{H A}$ and $\Delta$ di-nonS ${ }_{\mathrm{CS}}$. The $r^{2}=0.987$ value of PAGEFS was comparable with that obtained from HPLC analysis $\left(r^{2}=0.990\right)$.

The choice of the electrophoresis buffer was critical for the effective separation of all types of $\Delta$-disaccharides. Different types of buffers have been used for stacking and resolving gels as well as for the running buffer. The best separation was obtained using a buffer composed of $187.5 \mathrm{~mm}$ Tris- $\mathrm{HCl}$ and $187.5 \mathrm{~mm}$ Tris-borate buffer, $\mathrm{pH} 8.8$, for resolving gel polymerization. Higher concen-

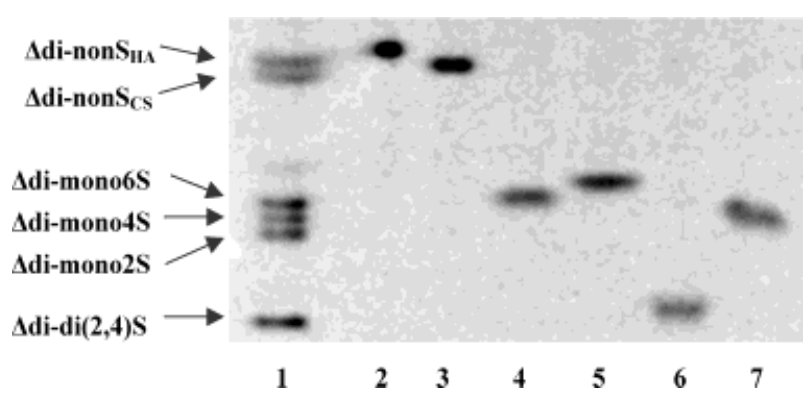

Figure 1. Analysis of standard $\mathrm{HA}$ and variously sulfated CS $\Delta$-disaccharides, derivatized with AMAC, by polyacrylamide gel electrophoresis. Analysis was done on a $25 \% \mathrm{~T} / 3.75 \% \mathrm{C}$ polyacrylamide gel with a stacking gel of $5 \% \mathrm{~T} / 1.5 \% \mathrm{C}$, at $400 \mathrm{~V}$, at $4^{\circ} \mathrm{C}$ for $45 \mathrm{~min}$. The electrophoresis buffer was $0.15 \mathrm{~m}$ Tris-borate, $\mathrm{pH}$ 8.8; the resolving gel buffer was a mix of $187.5 \mathrm{~mm}$ Tris-borate and $187.5 \mathrm{~mm}$ Tris- $\mathrm{HCl}, \mathrm{pH}$ 8.8; the stacking gel buffer was $0.36 \mathrm{M}$ Tris$\mathrm{HCl}, \mathrm{pH}$ 8.8. (A) Lane 1, mixture of $\Delta$-disaccharides; 2, $\Delta$ di-nonS $\mathrm{HA}_{\mathrm{HA}} ; 3, \Delta$ di-nonS $_{\mathrm{CS}} ; 4, \Delta$ di-mono4S; $5, \Delta$ dimono6s; 6, $\Delta$ di-di(2,4)S; 7, $\Delta$ di-mono2S.

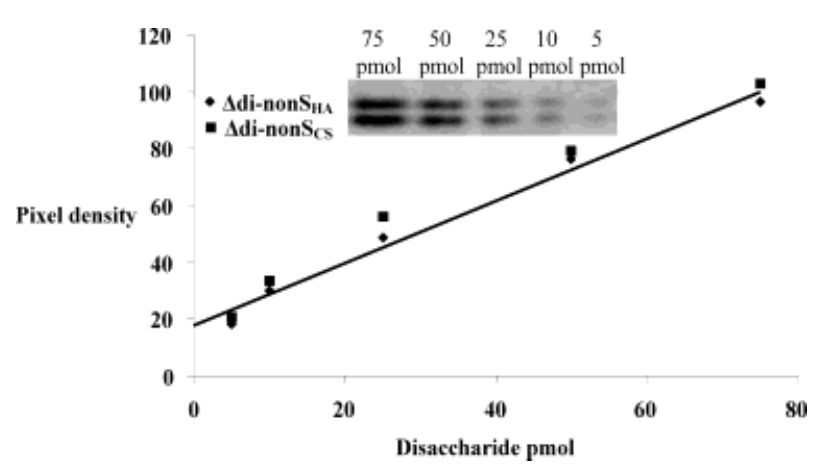

Figure 2. Quantitation of AMAC-derivatized $\Delta$ di-non $S_{H A}$ and $\Delta$ di-non $S_{C S}$ after separation by PAGEFS. Mixtures containing 5-75 pmol each of the indicated AMAC derivatives were separated by PAGEFS. The gel was then imaged using a CCD camera, and the images analyzed using a Gel Doc program and Microsoft Excel $\left(r^{2}=0.987\right)$.

trations of resolving gel buffer increased the heat formation during the run. The use of a buffer containing both Tris- $\mathrm{HCl}$ and Tris-borate is critical. In fact, it has already been demonstrated that Tris- $\mathrm{HCl}$ buffer in the resolving and stacking gel can separate successfully highly sulfated heparan sulfate oligosaccharides [18] and various sulfated CS $\Delta$-disaccharides [19]. The separation of sulfated $\Delta$-disaccharides using this buffer was actually very efficient, but the separation of nonsulfated CS and HA $\Delta$-disaccharides was very poor (Fig. 3, lane 2). Nonsulfated $\Delta$-disaccharides were successfully separated using a Tris-borate buffer, as described previously [20] (Fig. 3, lane 3 ), but the separation of sulfated $\Delta$-disaccharides was not complete. The effect of the borate buffer on disaccharide separation was described in CE analysis by 


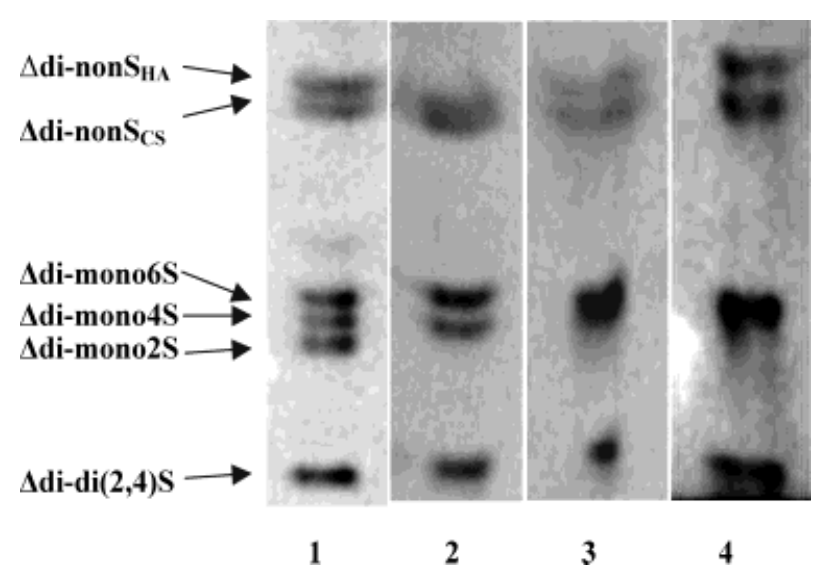

Figure 3. Analysis of standard HA and variously sulfated CS $\Delta$-disaccharides followed by derivatization with AMAC, with various buffer conditions in the resolving gel. The stacking gel consisted of polyacrylamide $5 \% \mathrm{~T} /$ $1.5 \% \mathrm{C}$ in a $0.36 \mathrm{M}$ Tris- $\mathrm{HCl}$ buffer, $\mathrm{pH} 8.8$, and the running buffer was $0.15 \mathrm{~m}$ Tris-borate, $\mathrm{pH}$ 8.8. The resolving gel consisted of $25 \% \mathrm{~T} / 3.75 \% \mathrm{C}$. Resolving buffers: lane 1 , $187.5 \mathrm{~mm}$ Tris-borate and $187.5 \mathrm{~mm}$ Tris- $\mathrm{HCl}, \mathrm{pH} 8.8$; 2, 0.375 м Tris-HCl, pH 8.8; 3, 0.375 м Tris-borate, $\mathrm{pH}$ 8.8; 4, $0.375 \mathrm{~m}$ Tris-borate and $0.375 \mathrm{~m}$ Tris- $\mathrm{HCl}, \mathrm{pH}$ 8.3.

Lamari and Karamanos [21], who demonstrated that carbohydrates can form anion complexes with borate under alkaline conditions, thus offering a better separation between nonsulfated $\Delta$-disaccharides. Based on these observations, a buffer containing both Tris- $\mathrm{HCl}$ and Trisborate in the resolving gel was used. Using this mixed buffer, the separation of sulfated and nonsulfated $\Delta$-disaccharides in the same run was achieved (Fig. 1). Different stacking gel and running buffer formulations were tested; the optimal choice of stacking gel buffer was $0.36 \mathrm{M}$ Tris- $\mathrm{HCl}, \mathrm{pH} 8.8$, and the best formulation for running buffer was $0.15 \mathrm{M}$ Tris-borate, $\mathrm{pH} 8.8$ (Fig. 3, lane 1). Lower $\mathrm{pH}$ on the buffers reduced the efficiency of separation of sulfated disaccharides (Fig. 3, lane 4).

\subsection{Application to the analysis of GAGs from human umbilical cord cultured and AoSMCs and comparison with HPLC}

The method was applied to study HA and CS $\Delta$-disaccharides isolated from a tissue (human umbilical cord) and a cell culture (AoSMCs), as described in Section 2 (Fig. 4A and Fig. 5A, respectively). Results of analysis of human umbilical cord disaccharides are shown in lane 2 of Fig. 4. Disaccharide separation identified and quantified disaccharides derived from HA and CS-4 and CS-6 sulfated chondroitin sulfate. As expected, the HA disaccharide is mainly represented (about $70 \%$ of total disac-
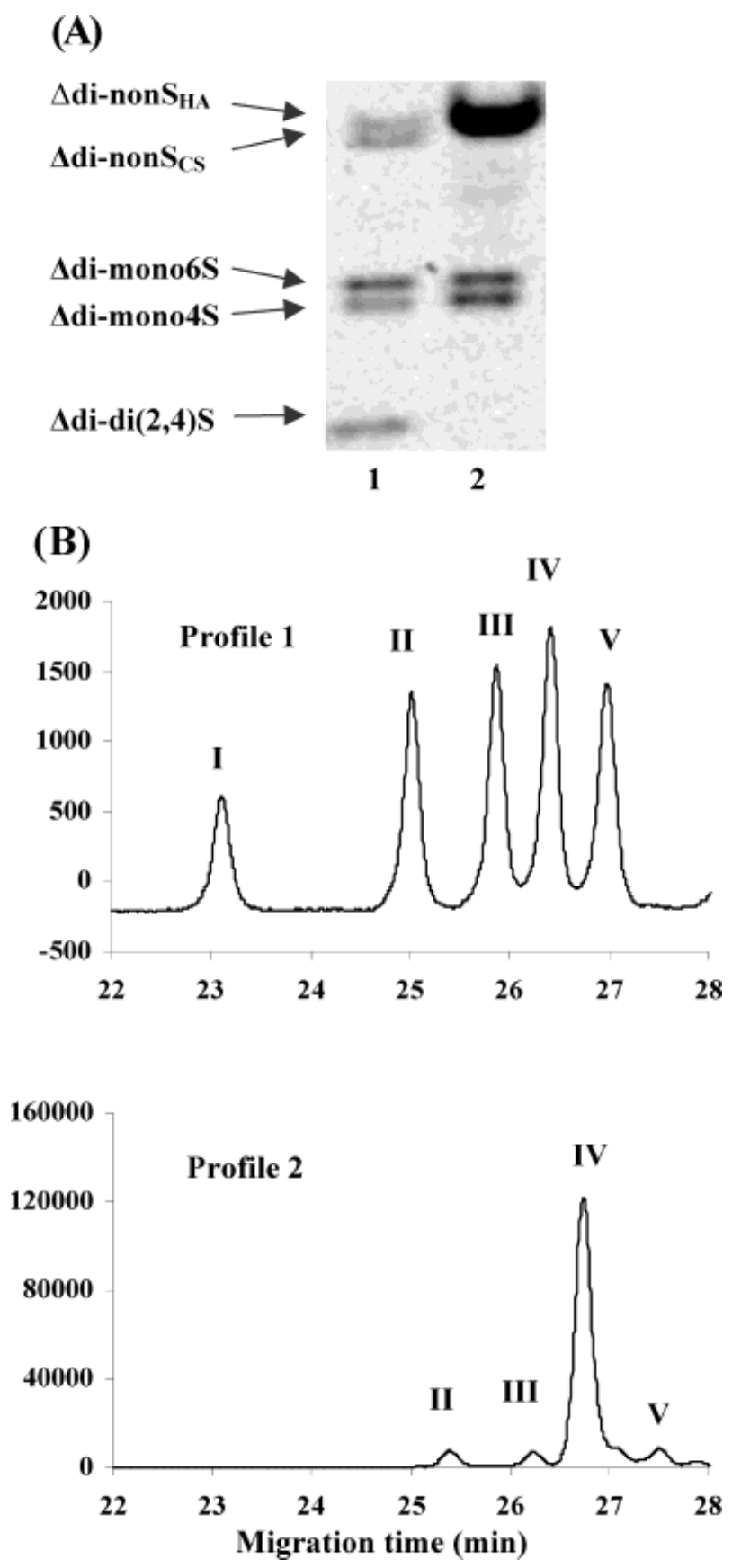

Figure 4. GAGs isolated from fresh human umbilical cord were digested with hyaluronidase SD and chondroitinase $A B C$. The products were derivatized with $A M A C$ and analyzed with PAGEFS and HPLC. (A) PAGEFS conditions in Fig. 1. Lane 1, mixture containing 100 pmol of each standard $\Delta$-disaccharide; 2, $\Delta$-disaccharide derived from human umbilical cord. (B) HPLC analysis was performed with a reversed-phase column $(\mathrm{C}-18,4.6 \times 150 \mathrm{~mm})$, and the products were detected with a fluorophore detector ( $\lambda$ ex $=442 \mathrm{~nm}$ and $\lambda \mathrm{em}=520 \mathrm{~nm}$ ). Separation of standard (profile 1) and derived (profile 2) $\Delta$-disaccharides from human umbilical cord. Peaks: I, $\Delta$ di-di(2,4)S; II, $\Delta$ dimono4S; III, $\Delta$ di-mono6S; IV, $\Delta$ di-nonS $\mathrm{HA}_{\mathrm{HA}}$ V V, $\Delta$ di-nonS ${ }_{\mathrm{CS}}$. 
(A)

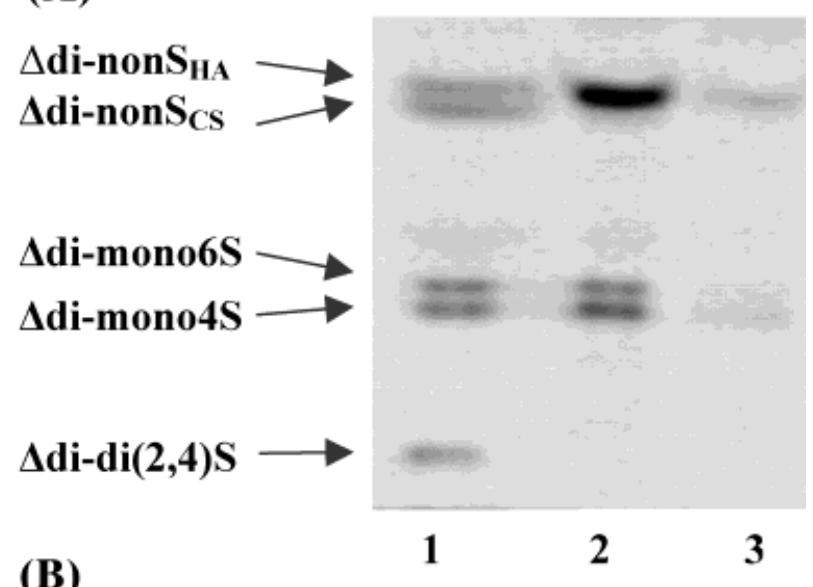

(B)

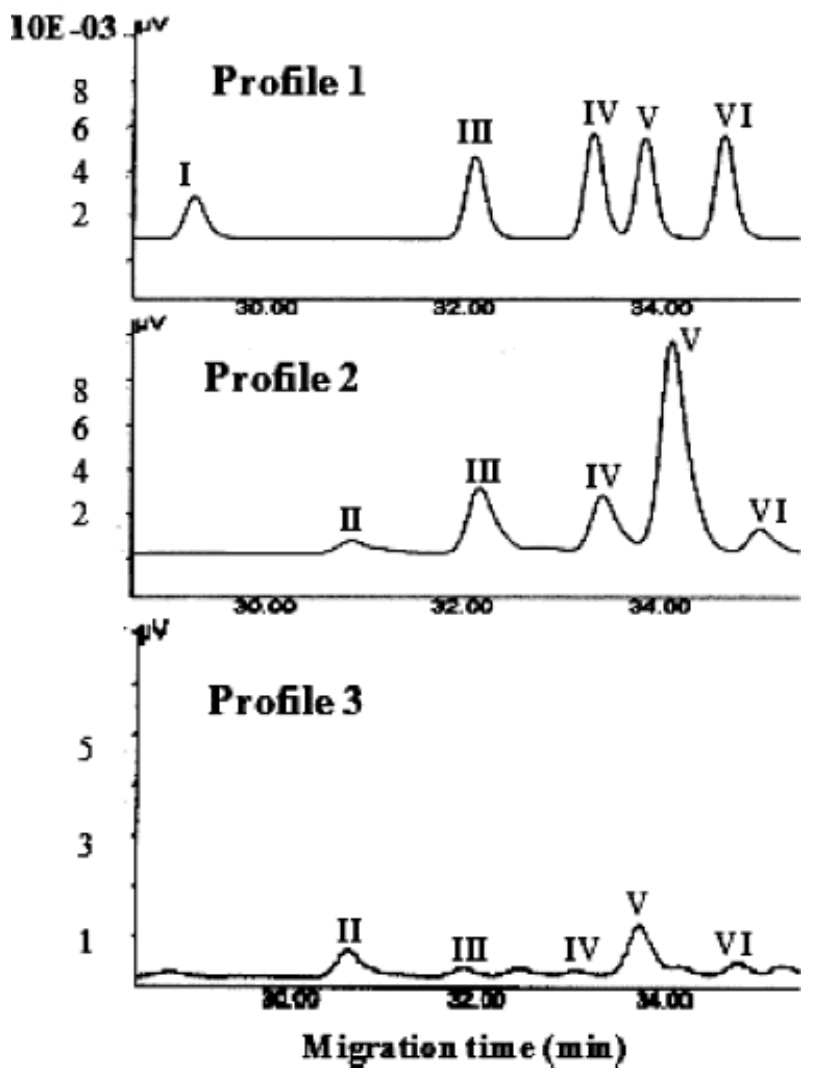

Figure 5. GAGs from the medium and the cell layer of AoSMCs were isolated and digested with hyaluronidase $\mathrm{SD}$ and chondroitinase $\mathrm{ABC}$. The products were derivatized with AMAC and analyzed with PAGEFS and HPLC. (A) PAGEFS conditions analysis as in Fig. 1. Lane 1, mixture containing $100 \mathrm{pmol}$ of each standard $\Delta$-disaccharide; 2 , derivatized $\Delta$-disaccharides from the medium of AoSMCs; 3, derivatized $\Delta$-disaccharides from the cell layer of AoSMCs. (B) HPLC analysis was performed as described in Fig. 4. Profile 1, HPLC analysis of a mixture of standard $\Delta$-disaccharides; profile 2,3 , separation of derived $\Delta$-disaccharides from the medium and cell layer of AoSMCs, respectively. Peaks: I, $\Delta$ di-di(2,4)S; II, $\Delta$ dimono4S; III, $\Delta$ di-mono6S; IV, $\Delta$ di-nonS ${ }_{\mathrm{HA}} ; \mathrm{V}, \Delta$ di-nonS $\mathrm{CS}_{\mathrm{C}}$. charides), whereas $\triangle \mathrm{Di} 4 \mathrm{~S}$ and $\Delta \mathrm{Di} \mathrm{SS}$ are almost in equal amounts. The separation and quantitation of disaccharides were confirmed by HPLC analysis (Fig. 4B, profile 2).

As far as the AoSMC disaccharides are concerned, PAGEFS separations are summarized in Fig. 5. PAGEFS results were in agreement with those of HPLC and showed that HA was particularly abundant in the medium, constituting $70 \%$ of the total amount of GAG (Fig. 5A, lane 2; Fig. $5 B$, profile 2). The $\triangle \mathrm{Di} 4 \mathrm{~S} / \Delta \mathrm{Di} \mathrm{SS}$ ratios in PAGEFS and HPLC were 2.1:1 and 2.3:1, respectively. The peak II in Fig. 5B was $\Delta$ di-mono2S. That was identified after co-injection of a sample with a commercial standard. CS present in the culture medium is mainly sulfated at C-4. As expected, only very small amounts of HA and CS were detected in the cell layer (Fig. 5A, lane 3; Fig. 5B, profile 3).

\section{Concluding remarks}

We described a powerful and flexible PAGEFS method to analyze HA- and CS-derived disaccharides after their derivatization with the fluorophore AMAC. The utility of this gel system is evident considering the lack of commercial gels described by Calabro et al. $[9,10,13]$ that are not longer available. The procedure proposed here is simple and rapid since 20 samples can be analyzed in one run (two minigels in one apparatus), requiring only $2 \mathrm{~h}$ for gel preparation and $\sim 1 \mathrm{~h}$ for electrophoresis. Moreover, this technique is of low cost since it does not require expensive equipment, in contrast to other approaches for carbohydrate analysis. The method has high sensitivity (less than 25 pmol of derived $\Delta$-disaccharides can be detected), and provides a fast and accurate tool for estimating the total amount of HA and various sulfated CS disaccharides in a small quantity of material. The applicability was examined by analyzing successfully the GAGderived $\Delta$-disaccharides from the culture medium and cell layer of a AoSMC culture and from human umbilical cord. The efficiency of the method was evaluated by comparing the results obtained from the analysis by PAGEFS with those by HPLC, which is a well accepted method for disaccharide analysis. The HPLC equipped with fluorescence detector achieves a higher sensitivity compared to PAGEFS, since $\Delta$ di-mono2S was detected only using HPLC. However, the latter technique requires more expensive equipment, HPLC runs are longer, only single samples can be analyzed at a time, and more sample volume is necessary. The data obtained suggest that the PAGEFS method may be a useful tool for a fast and sensitive screening of multiple samples. 
The authors wish to thank Prof. Markku Tammi for helpful discussions and Dr. Luigi Raio for providing the human umbilical cord. This work was sustained by funds from MUIR Cofin and F.A.R to G.D.L and from IRCCS (cryobank project) to G.P.

Received March 12, 2004

\section{References}

[1] Iozzo, R. V., Crit. Rev. Biochem. Mol. Biol. 1997, 32, 141-174.

[2] Karamanos, N. K., Syrokou, A., Vanky, P., Nurminen, M., Hjerpe, A., Anal. Biochem. 1994, 221, 189-199.

[3] Theocharis, A. D., Tsolakis, I., Tsegenidis, T., Karamanos, N. K., Atherosclerosis 1999, 145, 359-368.

[4] Theocharis, A. D., Theocharis, D. A., De Luca, G., Hjerpe, A., Karamanos, N. K., Biochimie 2002, 84, 667-674.

[5] Albertini, R., Ramos, P., Giessauf, A., Passi, A., De Luca, G., Esterbauer, H., FEBS Lett. 1997, 403, 154-158.

[6] Albertini, R., De Luca, G., Passi, A., Moratti, R., Abuja, P. M., Arch. Biochem. Biophys. 1999, 365, 143-149.

[7] Toole, B. P., Semin. Cell Dev. Biol. 2001, 12, 79-87.

[8] Jackson, P., Mol. Biotechnol. 1996, 5, 101-23.

[9] Calabro, A., Hascall, V. C., Midura, R. J., Glycobiology 2000, 10, 283-293.
[10] Calabro, A., Midura, R., Wang, A., West, L., Plaas, A., Hascall, V. C., Osteoarthritis Cartilage 2001, 9, S16-22.

[11] Goubet, F., Jackson, P., Deery, M. J., Dupree, P., Anal. Biochem. 2002, 300, 53-68.

[12] Wight, N. T., in: Comper, D. W. (Ed.), Extracellular Matrix, Hardwood Academic Publishers, Amsterdam, The Netherlands 1996, pp. 234-303.

[13] Calabro, A., Benavides, M., Tammi, M., Hascall, V. C., Midura, R. J., Glycobiology 2000, 10, 273-281.

[14] Okafo, G., Langridge, J., North, S., Organ, A., West, A., Morris, M., Camilleri, P., Anal. Chem. 1997, 69, 4985-4993.

[15] Lamari, F., Theocharis, A., Hjerpe, A., Karamanos, N. K., J. Chromatogr. B 1999, 730, 129-133.

[16] Mitropoulou, T. N., Lamari, F., Syrokou, A., Hjerpe, A., Karamanos, N. K., Electrophoresis 2001, 22, 2458-2463.

[17] Militsopoulou, M., Lamari, F. N., Hjerpe, A., Karamanos, N. K., Electrophoresis 2002, 23, 1104-1109.

[18] Turnbull, J. E., Gallagher, J. T., Biochem. J. 1988, 251, 597608.

[19] Karousou, E. G., Porta, G., De Luca, G., Passi, A., J. Pharm. Biomed. Anal. 2004, 34, 791-795.

[20] Rilla, K., Lammi, M. J., Sironen, R., Torronen, K., Lukkonen, M., Hascall, V. C., Midura, R. J., Hyttinen, M., Pelkonen, J., Tammi, M., Tammi, R., J. Cell Sci. 2002, 115, 3633-3643.

[21] Lamari, F., Karamanos, N. K., J. Liq. Chromatogr. Rel. Technol. 1999, 22, 1295-1317. 